\title{
A Study on the Management for College Students from the Perspective of Positive Psychology
}

\author{
Wan Fangfang ${ }^{1, a}$, Cui Bo ${ }^{1, b}$ \\ ${ }^{1}$ Medical College of Xi'an Peihua University, Xi'an, Shaanxi Province 710100, P.R. China \\ ayancong192@qq.com, b7542906@qq.com
}

Keywords: Positive psychology; Student management; Appreciation education; Positive psychological experience.

\begin{abstract}
From the perspective of psychology, this paper analyzes the existing disadvantages of contemporary university student management work, and put forward a kind of effective management methods for students. We explored the students' positive force, guided the students' positive qualities, stimulated the students' positive subjective initiative and potential ability by building a positive management system, creating a positive education environment, setting up the positive consciousness of management, advocating positive recognition education, By the education form of positive reinforcement, we made the students to obtain the biggest happiness and joy. This paper applies positive psychology to student management work, which can develop methods for the management for college students, guide students to establish positive health psychology, and realize the all-round development of body and mind of college students really.
\end{abstract}

\section{Introduction}

United Nations Educational Scientific and Cultural Organization pointed out in Higher education in twenty-first Century: the World Declaration on the prospect of action, that higher education requires a student-centered new perspective and a new model. The decision makers of the state and higher schools should take the students and their needs as the focus of their concern. According to this request, the management idea and the management method of university must make the corresponding change. In recent years, the university students' mental health has been paid more and more attention to, and various management methods have been explored. Among them, the management for college students from the perspective of positive psychology is becoming the direction of the university students' management worker studies. This paper have made a new exploration on the management of college students, and proposed a new management concept and management mode. The method is simple and easy to operate, and is more suitable for the management of students in different levels.

\section{The basic contents and main points of positive psychology}

"Positive psychology" is an important psychological strength rising at the end of the 20th century in western psychology, which was formally put forward by Seligman and Csik szentmihalyi in 2000 in positive psychology introduction published in the American psychologist[1]. It emphasizes the fact that psychology studies should shift from too much attention to psychological problems in the past to concern on human's active power, advocates a positive way to explain the psychological phenomenon, and seeks various factors to help all people obtain happiness in good condition in this process[2].

Every one of us has the advantages and disadvantages, which is the objective existence and no one can change that[3]. And positive psychology not only focuses on the disease, but also the power of attention; not only concerns patients with psychological problems, but also helps people's health; from people's actual potential and constructive virtue, a new interpretation to people's mental phenomenon is given in a positive way, human potential is developed, people's vitality is stimulated, and the ability and creativity of the people are promoted, which will enable us to get the greatest happiness and joy[4]. 
The main point of positive psychology: psychology should help all people to pursue happiness as its pursuit of value, promote the use of open and appreciate the point of view of others and things, and focus on the positive aspects of each individual; stress the positive approach to making a new interpretation of people's psychological phenomena and problems, and inspire everyone's inner strength.

\section{Basic features and management of Contemporary College Students Management}

\subsection{Student management center's deviation from mental health target}

Currently, most of the university students managements aim at the students' mental health, but in fact them still follow the previous negative psychology model[5]. The university students' managers often get used to take measures to help students to correct problems in the study and life, in order to train them to be good people[6].

Correcting the shortcomings does not means a good man, because good quality won't come into being disappear with the disappearance of shortcoming, only by excavating the potential of students, cultivating students' positive psychological quality, can managers make the mental health and student management work together[7].

\subsection{Single evaluation standard and ignorance of the students' diversity}

From the perspective of positive psychology, achieves the requirement of the employers. Colleges and universities should focus on cultivating the students' public quality such as virtue, professional morality and social responsibility. However, Overrules by one ticket is adopted by most of the university student managements, which results in the importance of being safe and the fear of campus safety accident. Under the guidance of this thought, the students trained by universities are disciplined and obedient; judging a student by these characters cannot avoid the partiality of evaluation and the ignorance of the development of students' diversification, which not do good to students.

\subsection{Punitive system's being more than incentive system}

People always grow with the affirmation and encouragement, and so do adolescent students. Praise can lead to a pleasant emotional experience, which makes people feel better; While criticism make people feel upset and angry[8]. Therefore, to raise people's consciousness, managers should formulate some incentive system, and attach great importance to the positive value of people.

Unfortunately, the historical tradition of the highly centralized makes people long accustomed to using high-pressure policy, accustomed to define the boundaries of human behavior negatively, most of the current system is punished. In the daily student management, we can see or hear "This is forbidden", this regulation can't achieve the desired management effect, but inspire student's rebellious attitude, which has the opposite effect.

\section{The new mode of contemporary university students' management}

The student management work is not only to prevent the occurrence of problems and to solve the problem after it occurs, the key is to help students form a good mental or behavioral pattern, fundamentally to reduce or to eliminate students' bad behavior. Managers make students grow up healthily by cultivating students' positive qualities and developing their positive energy, which is the work of positive psychology.

Therefore, according to the features of university students' management and the psychological characteristics of contemporary college students, aiming at the problems existing in the original management, such as student management center's deviation from mental health target, single evaluation standard and ignorance of the students' diversity, punitive system's being more than incentive system, it seems that we can convert the view, from the perspective of positive psychology to construct university students' harmonious management model. Giving the positive guidance to students, managers can help students with a positive attitude towards a series of issues related to academic, adaptive, emotional, and interpersonal relationships in study and life. This harmonious management model can help students overcome negative emotions, pay attention to people's positive 
value, arouse people's consciousness, which has a positive influence on the problems that the managers have to face and prevent in the student management work.

\subsection{Building a positive management system, creating a positive environment for education}

In the opinion of positive psychology, education are purposeful, planned, organized activities which promotes the full and harmonious development of students' bodies and mind, Only by relying on active organization system can education activities carry out. Positive psychology emphasizes any resource in schools is available, managers must take advantage of these resources which are in the students' daily life, Therefore, managers should be clear how to construct and take advantage of favorable conditions to help students build positive awareness of life and positive psychological quality, besides, managers should apply the concept of positive psychology to student management.

At first, universities should highlight the characteristics of higher professional education, establish a "people-oriented" management philosophy, besides, universities should serve the management education to create a good positive environment that encourages students to develop a positive experience, encourage students to success. At the same time, to create a good campus culture, universities should organize positive, healthy, diversified cultural and sports activities, and create a positive culture and public opinion.

\subsection{Transforming the idea, setting a positive sense of management}

Adolescent students almost have more or less problems, this is to rely on our small amounts of student management workers to help and solve don't be finished. Be blocked, the hydrophobic hydrophobic than led, as a result, positive psychology is very suitable for college students' education. Compare with traditional mental health "model", positive psychology is a kind of "health model", it says that in the process of education students, is more attention should be paid to the advantages of the students, rather than shortcomings, to create a positive attitude, see the strengths and weaknesses as heavy, to excavate the potential of students themselves.

But the establishment of this concept needs the change of educational idea for school leaders and teachers. Fully aware of and learn the idea of positive psychology, change ideas, eliminate the influence of the traditional "disease model", and establish the concept of "health model". Establish a scientific and diversified evaluation system, pay attention to the development of evaluation, and look at the students with the developing vision. Make individualized development planning for students, formulate the corresponding evaluation criteria, no longer blindly treat the evaluation of teachers as the leading, more join evaluation content and method should be used, and make the student to become the evaluation subjects.

\subsection{Advocate appreciation education}

American psychologist James said: "the most profound principle of human nature is to be appreciated by others". His study found that a man without an appreciation of the incentive can only play its ability of 20\%-30\%, and when he was inspired by the appreciation, the ability will play 3-4 times before the incentive[9]. Therefore, in our daily management work, the appreciation of the incentive is very important. We should recognize differences, respect for differences. Based on these, we should show praise for each student's progress, make students know their flash points, stimulate students' subjective initiative and the potential huge capacity, inspire the students effectively as with the "positive reinforcement" form of education, and finally promote students' progress and growth.

Appreciation education is not simply to say a few words of beauty, but to give students full of patience, perseverance, and remember the progress of every point of the students. The growth of the students is in the forward repeatedly, in the repeated forward, even if students have repeatedly, we shouldn't be disappointed, but to trust him, appreciate him and hug him. Let the students feel to be found, to be recognized, and students will hold more self-respect, self-confidence and self-reliance under the teacher's pride. 


\subsection{Provide positive psychological experience for students}

Successful experience can improve self efficacy, and the failure of many times will reduce people's perception of their ability to judge. In the positive psychology view, all people have the need to achieve their own needs, which will stimulate their potential positive forces and excellent quality. Therefore, the student management staff should update the management concept, treat the success of students as the primary task. Constantly inspire students to the pursuit of success, and create opportunities for students to provide help, put forward the appropriate requirements according to the actual situation of each student and personality characteristics, control the requirements to the student's "zone of proximal development", and constantly provide students with a positive psychological experience.

Modern management believes that management should be at the core of the human mind, and the first is to take control of the heart[10]. As a college student management worker, firmly seize the "person" of the factors, formulate the positive rules and regulations, optimize the management way of students, and establish a diversified evaluation mechanism, rather than to treat the scores as the only yardstick of student evaluation. Make all students can go beyond themselves, constantly forge ahead, through the completion of the positive psychological experience to accumulate experience, ultimately form the intrinsic positive forces and excellent quality, and get a better life.

\section{Conclusions}

In short, each student's psychology has a sunny side and a dark side. As still growing college students, teachers' active guide to get rid of the troubles of various negative factors is needed. Managers apply the positive psychology to student management work, only by constructing a positive management system, creating a positive environment for education, establishing a positive management awareness, advocating positive appreciation education, can managers guide the students' positive quality, stimulate students' active and subjective initiative and potential ability, expand the field of vision, achieve the overall development of college students. Besides, the harmonious management model for college students that is constructed on the positive psychology can enable students to obtain the greatest happiness and joy through the positive encouragement for students.

\section{References}

[1]. ZHOU Qin, SHI Guo-xing. Introduction to positive psychology[J]. Chinese Journal of mental health, 2006(2).

[2]. REN Jun, ZHANG Yi-bing. Positive psychology movement and Its Enlightenment to the construction of harmonious society in China[J]. Academic Forum, 2005(12).

[3]. REN Jun, LI Qian. Positive psychology: Current problems and future trends[J]. Journal of Shanghai Normal University( Philosophy \& Social Sciences Edition), 2014, 43(2): 140-146.

[4]. ZENG Qian. Probe into the work of the instructors in the management of students in Colleges and Universities[J]. Education and Teaching Research, 2010, 24(1): 63-66.

[5]. HUANG Yan. On the reform of management system and management concept in the harmonious management mode of University[J]. Journal of Guangdong AIB Polytechnic College, 2006(4).

[6]. XU Jin-gui. TANG Yu-xi. A preliminary study on the concept and operation mode of teacher management[J]. Teaching and Management, 2000(1).

[7]. XIONG Yong-chang. Construction of self education curriculum in schools to promote students' self development[J]. Educational Science Research, 2015, (4): 72-76.

[8]. TAN Bo, ZHOU De-xin. Game Analysis on the problem of "heavy punishment and light excitation" in safety management[J]. Industrial Safety and Environmental Protection, 2014(10). 
[9]. LI Sen-song. The positive energy of the appreciation education[J]. Survey of Education, 2016, 5(4): 31-32.

[10]. LIU Si-yang. Problems and Countermeasures of College Students' management[J]. Survey of Education, 2016, 5(11): 31-32. 